\title{
АВТОРСКОЕ ВИДЕНИЕ МИФОЛОГЕМЫ [WITСН] В ПРОЗЕ К.С. ЛЬЮИСА
}

В статье рассматривается концептуальная структура важнейшей для произведений жанра английского фэнтези мифологемь - [WITCH] на материале прозь К. С. Льюиса. Осуществляется детальный конщептуальный анализ данной мифологемь, посредством чего выделяются её авторские концептуальные признаки и анализируется видение образов колдуньи в прозе К.С. Льюиса.

Ключевые слова: концептуальная структура, мифологема

The article considers the conceptual structure of the mythologeme that is key to the works of the English fantasy genre [WITCH]. The research is based on the material of J. C.S. Lewis's prose. A detailed conceptual analysis of the mythologeme is performed, whereby the conceptual features of the author's personal vision of the mythologeme are distinguished and the vision of the images of the witch in Lewis's prose is analyzed.

Keywords: conceptual structure, mythologeme

В данной работе анализируется авторское видение мифологемы [WITCH] в прозе К.С. Льюиса. Прежде всего, считаем необходимым дать определение краеугольному для нашего исследования понятию - понятию "мифологема". Определение мифологемы является несколько более сложной задачей, чем определение понятия "миф", хотя бы в силу того, что первое является намного более молодым и менее исследованным, нежели понятие мифа.

Понятие мифологемы было введено в употребление К. Г. Юнгом, в частности, подробную характеристику мифологемы можно найти в монографии "Душа и миф: шесть архетипов". Несмотря на молодость, термин "мифологема" уже занимает прочное положение в современной науке, причём, не только в 
лингвистике, мифологии и лингвокультурологии, но также таких науках, как политология, искусствоведение, театроведение, история, археология и т.д. Именно мифологема, в отличие от обычных лексем, чаще всего несет культурную и историческую нагрузку, без которой порой невозможно выявить уникальность той или иной лингвокультурной сообщности, понять её "самость" и внутреннее я.

Мифологемы, безусловно, - лексемы особого рода, поскольку часто являются терминами без денотатов, однако несут в себе огромное количество признаков, таких как, экспрессивность, эмоциональность, историчность и т.д. С.И. Питина определяет мифологему как дискретную единицу коллективного сознания, концепт, отражающий объекты возможных миров, который в вербальной форме представлен в национальной памяти носителей языка. [Питина 2002: 26].

Итак, что же представляет собой мифологема? По нашему мнению, это некая первичная сюжетная схема, кросскультурная либо национальная идея, встречающаяся в фольклоре разных народов, перешедшая из мифа в эпос и волшебную сказку, затем в рыцарский роман и т. п. Так, сложно найти народ, в чьем эпосе отсутствует образ колдуньи, волшебницы, либо ведьмы. Мифологемы, несомненно, представляю интерес для исследователя, поскольку несут в себе огромную историческую память, а также аккумулируют культурные ценности нации. В этой связи, мифология как таковая предствляет собой ценнейший пласт для кросс-культурных и межнаучных исследований.

Определив ключевое для нашего исследования понятие, считаем возможным перейти к более подробному описанию нашего анализа.

Объектом исследования являются средства вербализации мифологемы [WITCH] во всех семи книгах из Нарнианы К.C. Льюиса. В ходе анализа нами применялись такие методы, как количественный анализ, концептуальный анализ, словарный анализ, а также элементы интроспекции. При этом основная гипотеза настоящего исследования состоит в том, что данная мифологема в прозе К.С. Льюиса обладает собственной уникальной структурой, которая, в свою очередь, имеет своеобразную ядерно-периферийную конфигурацию. 
В ходе работы ставилась цель определить, обладает ли видение К.С. Льюиса в его "Хрониках Нарнии" своей авторской спецификой. Если да, то в чём она состоит, и какие нестандартные черты образы колдуньи имеются в работах писателя? Насколько его авторское видение образа колдунью пересекается с общепринятым, т.е. "словарным"?

Прежде всего, необходимо рассмотреть так называемое "стандартное" (общепринятое) видение мифологемы. Для анализа мы обратились к моноязычным англо-английским словарям, таким, как Longman Dictionary of Contemporary English. Словарь даёт следующее определение слову [WITCH]:

1 a woman who is supposed to have magic powers, especially to do bad things

2 informal an insulting word for an old or unpleasant woman

Данное определение помогает выделить следующие базовые признаки колдуньи в английском языке: evil, female person, magic, old age, power, unpleasantness.

В целом, в ходе исследования было задействовано 5 моноязычных словарей. Проведенный лексический анализ позволяет выделить 20 основополагающих признаков, которые связаны с образом ведьмы. Исходя из этого, словарное ядро мифологемы [WITCH] можно представить следующим образом:

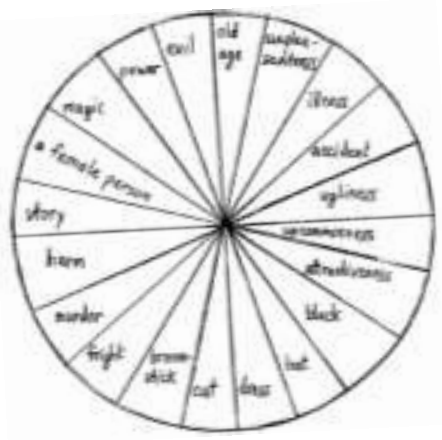

Рис. 1. Словарное "ядро" мифологемы [WITCH] 
На втором этапе исследования был осуществлён анализ авторских признаков мифологемы [WITCH] в творчестве Льюиса, которая оказалась намного чаще вербализована, нежели мифологема [MAGICIAN]. В ходе данного исследования нами было выявлено и проанализировано 225 СФЕ во всех семи книгах "Хроник Нарнии" К.С. Льюиса, в которых было выявлено 263 случаев непосредственной вербализации мифологемы (лексемы) [WITCH] (напомним, что мифологема [MAGICIAN] вербализована лишь 58 раз, т.е. более, чем в 4,5 раза реже, нежели мифологема [WITCH] ). Проведенный анализ позволил выделить 18 базовых элементов концептоферы: "age"/ «возраст», "animals" «животные», "beauty” / «красота», "body”(“part of body”)/ «тело»/ «часть тела», “cruelty" / «жестокость», "death" / «смерть», “enmity” (hatred) / «вражда» (ненависть), "family" / «семья», “fear" / «страх», "life" / «жизнь», "magic" / «волшебство», "mythical creatures" / «мифические существа», “power” / «мощь, могущество», "royalty" / «королевская семья» (королевская власть), “size” (height) / «размер» (рост), “stupidity”/ «глупость», "winter" / «зима», “world" / «мир».

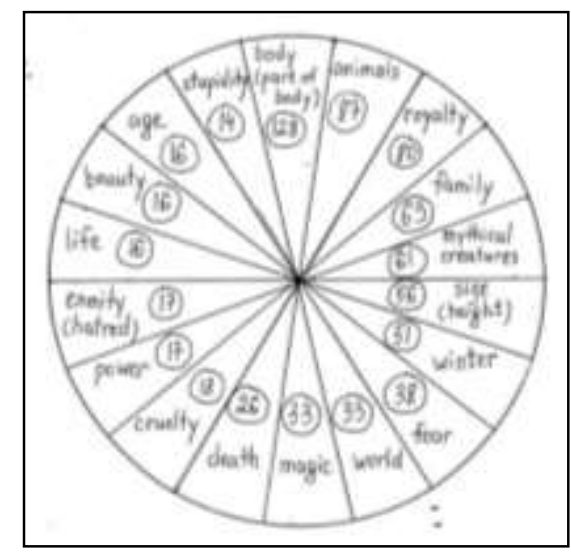

Рис. 2. Авторское ядро концепта [WITCH] в произведениях К.С. Льюиса 
Необходимо отметить, что мифологема [WITCH] в Нарниане вербализована почти в 2,5 раза реже, нежели мифологема [WIZARD] (343 случая вербализации против 827). Тем не менее, несмотря на этот факт, авторский образ волшебницы также обладает развитой и разнообразной структурой, за счет чего Льюису, безусловно, удается создавать яркие и неповторимые персонажи. Из вышеприведённой схемы очевидно, что главным элементом концептосферы у К.С. Льюиса является "body" ("part of body"), что, судя по всему, также является важнейшей составляющей образности произведения и "правдоподобности " персонажей:

(1) A few minutes later the Witch herself walked out on to the top of the hill and came straight across and stood before Aslan. The three children who had not seen her before felt shudders running down their backs at the sight of her face; and there were low growls among all the animals present. Though it was bright sunshine everyone felt suddenly cold. The only two people present who seemed to be quite at their ease were Aslan and the Witch herself. It was the oddest thing to see those two faces - the golden face and the dead-white face so close together. Not that the Witch looked Aslan exactly in his eyes; Mrs Beaver particularly noticed this.

(The Lion, the Witch and the Wardrobe, Chapter 13)

Как видим, К.С. Льюис особое внимание уделяет описанию внешности персонажей, таки образом мастерски "вылепливая" персонажа и целиком погружая читателя в атмосферу произведения.

Весьма удивительным является такой элемент концептосферы, как "stupidity", который, хоть и реализован лишь 14 раз (против 128 раз в случае с главным элементом "body" ("part of body")), представляет несомненный интерес, поскольку является у Льюиса лишь ассоциацией с образом колдуньи, но не колдуна. Тем не менее, глупость скорее рассматривается не как характеристика самих колдуний, но как характеристика тех, кого они считают нижестоящими по положению, поскольку, например, слово "fool" часто используется при обращении ведьм к окружающим: 
(2) But the Witch had very good ears. "Fool!" came her voice and she leaped off the horse. "Have you forgotten that I can hear men's thoughts? Let go the boy. If you attempt treachery I will take such vengeance upon you as never was heard of in all worlds from the beginning."

(The Magician's Nephew, Chapter 8)

Таким образом, мифологема [WITCH] в произведениях Льюиса обладает четким набором авторских признаков, таких как "royalty", "stupidity", "mythical creatures" и т.д., что, безусловно, помогает автору в создании образности произведения и погружении читателя в магическую атмосферу саги. При этом, "пересечение" авторского видения мифологемы Льюиса со "стандартным" (словарным) происходит лишь по таким базовым признакам как "magic" и "power" и "age".

\section{ЛИТЕРАТУРА}

1. Питина С.А. Концепты мифологического мышления как составляющая концептосферы национальной картины мира / Челяб. гос. ун-т. Челябинск, 2002. 191 с.

2. Степанов Ю.С. Константы: Словарь русской культуры. - М.: Академический Проект, 2001. 990 c.

3. Юнг К.Г. Душа и миф: шесть архетипов. Пер. с англ.-К.: Государственная библиотека Украины для юношества, 1996.- 384 с.

4. Longman Dictionary of Contemporary English, 2000

5. Longman Dictionary of English Language and Culture, 2000

6. Longman Essential Activator, 2000

(C) Сафина Н.Н., 2021 г. 